\title{
LA VIOLENCIA POLÍTICA ENTRE EL DELITO POLÍTICO Y EL TERRORISMO
}

ANDRÉS ROSLER

Andrés Rosler es Investigador del CONICET

y Profesor en la Facultad de Derecho

de la Universidad de Buenos Aires.

e-mail: andres.rosler@gmail.com

\section{INTRODUCCIÓN}

En una época en la cual el terrorismo ha cobrado singular vigencia, quisiera discutir en este trabajo la noción de violencia política, tanto conceptual cuanto normativamente. Mientras que la discusión conceptual gira alrededor de la caracterización del término, la discusión normativa se concentra en cómo debería ser tratada la violencia política, i.e., qué relación guarda dicha forma de violencia con su contraparte común, que podríamos denominar simplemente como «violencia criminal». Finalmente, quisiera decir algo acerca de la relación entre la valoración y la explicación de la violencia política en las ciencias sociales o humanas. Por momentos es difícil resistir la impresión de que, a pesar de su auto-comprensión usual, las ciencias sociales no rechazan a la violencia política, o lo hacen solamente de manera parcial (rechazando ciertos ejemplos de violencia política, pero no otros), quedándose a medio camino entre la neutralidad axiológica del viejo positivismo y la ciencia social políticamente comprometida.

En lo que sigue, se caracterizará primero brevemente la noción de violencia política. Luego se discutirá, desde un punto de vista, que en un sentido bastante vago podría ser llamado «histórico-conceptual», qué clase de relación guarda la violencia política frente a la violencia «común», ordinaria, o simplemente no política. Mientras que algunos (los defensores de la tesis que llamaremos «liberal») creen que la violencia política es moralmente superior a su contraparte común, otros (los defensores de la tesis que llamaremos «soberana») creen exactamente 
lo contrario, particularmente a raíz del desafío representado por el terrorismo. Finalmente, quisiera indicar que la ciencia social debe tomar partido por una tesis o la otra, sin poder permanecer neutral al respecto.

\section{VIOLENCIA}

En nuestra época la idea misma de violencia goza de una muy mala prensa: «Hoy, la violencia parece haber perdido toda legitimidad en el espacio político, al punto de significar el mal absoluto. Es ella la que la sociedad, unánime, debe proscribir y combatir, tanto en su seno como afuera de ella» ${ }^{1}$. Pero, tal como suele suceder con aquello que tiene muy mala prensa, es muy difícil poder caracterizarlo con alguna precisión ya que a nadie le gusta que le digan que lo que hace es violento y, probablemente, de modo recíproco, la mala prensa tenga a su vez algo que ver con esta imprecisión conceptual. La terminología empleada por los Estados también ha contribuido a la imprecisión, ya que por razones ciertamente políticas, más precisamente conservadoras, los Estados designan sus propias actividades en términos de «fuerza» (v.g. «fuerza policial», «fuerzas del orden», etc.), mientras que suelen considerar a todo acto insurgente como violento por definición ${ }^{2}$.

Convendría dejar de lado entonces el discurso normativamente contaminado del Estado -y el de sus enemigos por supuesto- sobre la caracterización de la violencia para tratar de buscar una descripción lo suficientemente ecuménica que impida tanto una naturalización nietzscheana de la violencia ${ }^{3}$, cuanto su conversión en

\footnotetext{
${ }^{1}$ Michel Wieviorka, La Violence, Paris, Hachette, 2005, pp. 67-68.

2 Ver Cecil A. J. Coady, Morality and Political Violence, Cambridge, Cambridge University Press, 2008, pp. 23-24. Dicho sea de paso, un defensor del sindicalismo anarquista y por lo tanto enemigo del Estado como Georges Sorel toma el camino inverso ya que reivindica la violencia en perjuicio de la fuerza, precisamente porque la fuerza tiene connotaciones estatales y burguesas mientras que la violencia se propone destruir la opresión estatal: «la fuerza tiene como objeto imponer la organización de determinado orden social en el cual gobierna una minoría, mientras que la violencia tiende a la destrucción de ese orden. La burguesía ha empleado la fuerza desde el comienzo de los tiempos modernos, mientras que el proletariado reacciona ahora contra ella y contra el Estado mediante la violencia». Georges Sorel, Reflexiones sobre la violencia, Madrid, Alianza, 1976, p. 231.

${ }^{3}$ Nietzsche creía que «la vida actúa esencialmente (...) ofendiendo, violando, despojando, aniquilando, y no se la puede pensar en absoluto sin ese carácter». Friedrich Nietzsche, Genealogía de la moral, Madrid, Alianza, 2008, p. 98.
} 
una misteriosa patología anti-pacifista. Semejante división del trabajo en análisis conceptual y valorativo permite evitar la petición de principio de las definiciones estatales o insurgentes de la violencia.

La palabra misma «violencia» sugiere la violación de algo, pero no queda del todo claro qué es precisamente aquello que es violado. En realidad, nos hemos acostumbrado a decir que algo es «violento» para expresar nuestro rechazo, de tal forma que, por ejemplo, en Argentina se ha vuelto cuasi-proverbial creer -entiendo que gracias a una banda de rock- que «violencia es mentir», lo cual en el mejor de los casos es una metáfora para expresar que mentir está (muy) mal. Por lo demás, en muchas ocasiones cuando queremos denunciar grandes injusticias decimos precisamente que son violentas para llamar la atención y enfatizar la necesidad de que se debe hacer algo al respecto.

Sin embargo, esta equiparación literal entre la violencia y la inmoralidad, es decir, entre una especie y el género, y la consiguiente moralización del término, no solamente provoca que la idea misma de violencia se nos escurra de las manos (¿qué no sería violento en caso de que la inmoralidad y la violencia fueran sinónimos?), sino que además implicaría que cada vez que nos enfrentáramos a una falta moral podríamos actuar violentamente. Los últimos acontecimientos que son de público conocimiento me eximen de detallar el peligro que podría ocasionar la asíllamada «violencia simbólica», particularmente a juzgar por la reacción que provocan las caricaturas anti-religiosas en algunos creyentes. Si la violencia simbólica no puede justificar la violencia literal contra sus autores, ya que en realidad la violencia simbólica es obviamente distinta a la literal, entonces habría que preguntarse cuál es el sentido de que lleven el mismo nombre. Solamente provoca confusión ${ }^{4}$.

Dado el riesgo que corremos al seguir concepciones moralizadoras de la violencia según las cuales cualquier acto que merezca nuestra desaprobación es violento, es preferible una noción minimalista según la cual la violencia tiene lugar en caso de un daño físico sufrido por una persona. Nadie podría negar, por ejemplo, que

4 Juan Altusio (Johannes Althusius) también creía que, por ejemplo, en el caso de un tirano, hay que responder «con palabras, cuando es solamente con palabras que el tirano viola el culto de Dios y ataca los derechos y fundamentos del Estado; se puede resistir por la fuerza y por las armas cuando él ejerce la tiranía a mano armada y desplegando la fuerza». Politica Methodicae Digesta, § 63, cit. en Mario Turchetti, Tyrannie et tyrannicide de l'Antiquité á nos jours, Paris, Presses Universitaires de France, 2001, p. 559. 
una persona literalmente golpeada es víctima de violencia. En este caso, sin duda, el daño da lugar a una valoración moral negativa pero sin llegar a confundir la violencia con la violación de una norma moral, ya que el daño en cuestión es fácilmente perceptible sin tener que recurrir al razonamiento moral.

Ciertamente, el minimalismo conceptual no está exento de riesgos, sobre todo si, sobre la base de alguna versión del dualismo entre el alma y el cuerpo, la noción de daño físico excluyera casos que merecieran ser considerados violentos como lo son algunos serios abusos psíquicos. Por otro lado, la noción de daño psíquico podría adolecer de problemas muy similares a los de las concepciones moralizadoras de la violencia, si permitiera que la determinación del daño psíquico dependiera del sujeto afectado antes que de un estándar imparcial. Imaginemos el caso de un vegetariano dispuesto a matar a los accionistas de una compañía productora de embutidos, sin mencionar el hecho de que este mismo vegetariano podría acometer la misma acción pero sin tener que invocar la noción de daño psíquico sufrido por él, sino que podría invocar directamente el evidente daño físico ocasionado a la materia prima de los embutidos.

Sin embargo, podemos imaginar el caso de víctimas pertenecientes a ciertas instituciones (en el sentido lato de la expresión) relativamente benevolentes en términos físicos pero devastadoras en términos psíquicos. En este último escenario sería muy difícil resistir la conclusión de que la violencia sería una forma apropiada para lidiar con dichas instituciones. Habiendo hecho esta aclaración, y dado que nos interesan los casos usuales de violencia política, en aras de la argumentación vamos a proceder sobre la base de la concepción minimalista de violencia lo suficientemente ajustada para hacer lugar al daño psíquico 5 .

Si bien la violencia deriva paradigmáticamente de ciertos actos, sería un error creer que la violencia no puede ser ocasionada por inacción u omisión. En efecto, nadie niega que pegarle un tiro a alguien es un acto violento. Sin embargo, para no poca gente si bien dejar morir de hambre a alguien es ciertamente inmoral, no por eso es necesariamente violento, o en todo caso no es tan violento como pegarle un tiro. Sin duda, existe una diferencia conceptual entre actuar y omitir, la cual puede ser fácilmente sincronizada con la distinción entre violencia subjetiva y estructural ${ }^{6}$.

${ }^{5}$ Vittorio Bufacchi, Violence and Social Justice, Londres, Palgrave MacMillan, 2007, pp. 41-44. Allí el autor habla de la violencia como la violación de la «integridad» de la persona.

${ }^{6}$ Sobre la distinción entre violencia «subjetiva» y «estructural», ver Cecil A. J. Coady, op. cit., p. 26. 
La cuestión es si dicha diferencia es moralmente relevante, i.e., si esta distinción no solamente apacigua nuestra conciencia, sino que a la vez es moralmente correcta.

Probablemente, la diferencia real entre actuar y omitir se deba a que existe cierta conexión entre víctima y victimario, ya que la persona que muere por un disparo suele estar cerca del que jala el gatillo, mientras que la relación entre nosotros y aquellos a los que dejamos morir suele ser bastante impersonal o despersonalizada, ya que las víctimas de inanición -a pesar de que podríamos evitarlo sin grandes costos de nuestra parte- no solamente suelen estar muy lejos sino que además ni siquiera sabemos quiénes son.

La distinción entre actuar y omitir suele ir reforzada por la distinción entre querer y prever ${ }^{7}$. En efecto, la distinción moral entre actuar y omitir parece subsistir porque por momentos sobreestimamos el punto de vista de la intención y la relación espacial entre agente y víctima, y subestimamos el punto de vista de las víctimas y por lo tanto la gravedad de las consecuencias de nuestros actos, a pesar de que para la víctima la cuestión clave no es la intención última de la agresión o qué tan lejos esté el victimario, sino la violencia en sí misma. De hecho, el hambre hoy en día es mucho más letal que el homicidio o la guerra, y sin embargo algunos se resisten a poner a la par los actos de guerra y los embargos comerciales -si no es que aceptan los primeros pero desaprueban los segundos-, a pesar de que los embargos pueden provocar muchísimas más muertes que los actos de guerra. Otra vez, es indudable que la previsión y la intención son dos estados mentales diferentes. La cuestión es si la distinción es moralmente relevante. Después de todo, el derecho interno es mucho más exigente que nuestra psicología estándar ya que criminaliza no solamente, v.g. al homicidio intencional sino también el homicidio culposo o negligente.

\section{VIOLENCIA COMÚN Y VIOLENCIA POLÍTICA}

Habiendo descripto qué entendemos por violencia, debemos ahora distinguir entre la violencia «común» o meramente «criminal» y la violencia «súper», o "política». A los fines de este trabajo entenderemos por violencia simplemente criminal aquella que es injustificable, incluso desde el punto de vista de quien

\footnotetext{
${ }^{7}$ Las dos distinciones pueden ser combinadas. Ver Vittorio Bufacchi, op. cit., p. 96.
} 
comete el acto violento. Quien comete un acto de violencia común, como diría Hobbes, «acepta» internamente la ley que prohíbe la violencia común, pero no la «observa» externamente ${ }^{8}$. En la terminología algo más elaborada de Kant, el que comete un acto de violencia común entiende a su acción «como una excepción a la regla» que prohíbe actuar violentamente, por lo cual «no hace más que desviarse de la ley (aunque deliberadamente)»; es más «puede a la vez detestar su propia transgresión y desear sólo eludir la ley, sin negarle formalmente obediencia» ${ }^{9}$. De ahí que Hegel sostenga que el castigo es el derecho del delincuente porque está contenido en la máxima de su acción ${ }^{10}$. Nadie comete un crimen (o al menos cierta clase de crímenes) sin contradecirse.

La violencia principista, en cambio, actúa al servicio de una causa precisamente política, y lo hace «siguiendo la máxima de una regla adoptada como objetiva (como universalmente válida)», de tal forma que «rechaza la autoridad de la ley misma (...) y convierte en regla de su acción obrar contra la ley; por tanto, su máxima no sólo se opone a la ley por defecto (negative), sino incluso dañándola (contrarie) o, como se dice, diametralmente, como contradicción (digamos, de un modo hostil)» ${ }^{11}$. En la terminología de Hart, el delincuente político ni se ve obligado a obedecer, ni cree que tiene la obligación de hacerlo ${ }^{12}$. Como bien dice Kant, quien desobedece a la ley por principio contradice a la ley, pero no por eso se contradice necesariamente a sí mismo.

Ciertamente, es la causa a cuyo servicio actúa la que explica la pretensión de justificación universalizante del que ejerce violencia política. Por supuesto, como decía Tu Sam, la justificación puede fallar. Pero al menos tiene sentido ensayarla. Después de todo, decir que algo es un crimen a primera vista solamente implica que se trata de una conducta prohibida, i.e. que va en contra del derecho. Además, la aspiración a la universalización suele ir acompañada por un fuerte componente

\footnotetext{
${ }^{8}$ Thomas Hobbes, Elementos filosóficos. Del ciudadano, traducción de Andrés Rosler, Buenos Aires, Hydra, 2010, pp. 278-279.

9 Immanuel Kant, Metafísica de las costumbres, Madrid, Tecnos, 1989, p. 153.

${ }^{10}$ Georg W. F. Hegel, Principios de la Filosofía del Derecho, 2da. ed., Barcelona, Edhasa, 1988, p. 161.

${ }^{11}$ Immanuel Kant, Metafísica de las costumbres, op. cit., p. 153.

12 La violencia política entonces puede ser descripta como una obediencia de segundo orden, una obediencia a un principio superior. Ver Raffaele Laudani, Disobedience in Western Political Thought, Cambridge, Cambridge University Press, 2013, pp. 27 y 42.
} 
sacrificial o de abnegación, ya que la justificación o principio que inspira el acto hace que el agente esté dispuesto a dar la vida por su causa.

El debate, ciertamente, está lejos de ser nuevo. Pensemos en el Bruto de Shakespeare (no es un juego de palabras), quien en Julio César ofrece al pueblo «razones públicas (...) de la muerte de César» y además expresa que está dispuesto a que le hicieran exactamente lo mismo a él para el caso de que él se convirtiera en otro César. En efecto, cuando Antonio declama estar dispuesto a ser «amigo... de todos y amarlos... a todos» los que mataron a César, a condición de que le dieran «las razones de por qué y en qué César era peligroso», Bruto quizás en un exceso de confianza le responde: «Nuestras razones están tan llenas de buenas consideraciones que si fueras tú, Antonio, el hijo de César, estarías satisfecho». Y agrega: «Si no, esto sería un espectáculo salvaje» ${ }^{13}$. Sin embargo, no es ninguna novedad que no todos compartían el entusiasmo de Bruto por la muerte de César. Por ejemplo, Tácito cuenta en sus Anales que «la muerte del dictador César pareció a unos la acción más deplorable y a otros la más hermosa» ${ }^{14}$.

\section{¿VIOLENCIA POLÍTICA?}

Antes de continuar, debemos tratar una objeción bastante difundida entre quienes se dedican a la teoría política, según la cual la expresión «violencia política», bien entendida, es en el fondo una contradicción en sus términos. Ciertamente, se trata de una objeción cuya zona de confort está bastante lejos de la obra de pensadores como Georges Sorel, Carl Schmitt o René Girard - para dar algunos nombres solamente-. En realidad, para estos autores la conexión entre violencia y política en lugar de ser imposible antes bien tiende a ser necesaria. Es más, la conexión entre violencia y política puede ser tan obvia para algunos que puede dar lugar a expresiones tan exquisitamente ambiguas como la siguiente de Salustio: «si

\footnotetext{
${ }^{13}$ William Shakespeare, Julius Caesar, Oxford, Oxford University Press, 1984, pp. 170-171, Ill.i. 220 ss.

${ }^{14}$ Tácito, Anales, I.8. La polémica estuvo lejos de agotarse en la época de César. Por ejemplo, mientras que el más ilustre de los defensores históricos de la primera posición (magnicidio) quizás sea Dante Alighieri, uno de los defensores más conocidos de la segunda posición (tiranicidio) tal vez lo sea Tomás de Aquino. Ver Thierry Sol, Fallait-il tuer César? L'argumentation politique de Dante à Maquiavel, Paris, Dalloz, 2005.
} 
Catilina no se hubiera adelantado a dar ante el Senado la señal a sus cómplices, aquel día se habría consumado el crimen más horrible desde la fundación de la ciudad de Roma» ${ }^{15}$.

Por lo demás, la conexión entre violencia y política se ha vuelto un lugar común en las ciencias sociales merced a la manera en que, v.g., Max Weber entendía precisamente a la política. Para Weber, todo grupo «político» en sentido estricto se caracteriza por su recurso a la violencia. Esto se debe a la desconfianza weberiana en la posibilidad de entender la actividad política en términos de una meta o fin peculiar, sin exceptuar de dicha dificultad al Estado, y de ahí la necesidad de comprender la política fundamentalmente a través del medio que emplean quienes practican dicha actividad ${ }^{16}$.

Sin embargo, para Hannah Arendt y sus acólitos deliberativistas todo acto violento no solamente no puede ser político sino que es en realidad «anti-político» ${ }^{17}$. En efecto, según Arendt

«lo que hace del hombre un ser político es su facultad de acción; le permite encontrarse con sus pares, actuar en concierto, y alcanzar metas y emprendimientos que nunca habrían entrado en su mente, qué decir en los deseos de su corazón, si no se le hubiese dado este don -el de embarcarse en algo nuevo (...) Ninguna otra facultad excepto el lenguaje, ni la razón ni la consciencia, nos distingue tan radicalmente de todas las especies animales» ${ }^{18}$.

Ciertamente, hasta un arendtiano admitirá que toda comunidad política parece estar "fundada en una violencia homicida», y no cualquier violencia sino fraterna además ${ }^{19}$; después de todo, los deliberativistas no son anarquistas, i.e. los únicos

\footnotetext{
${ }^{15}$ Salustio, Conjuración de Catilina, XVIII.8.

${ }^{16}$ Max Weber, Wirtschaft und Gesel/schaft, Tübingen, Mohr, 1980, p. 30.

17 Hannah Arendt, «On Violence», en: Crises of the Republic, Nueva York, Mariner Books, 1972, p. 160. Agradezco a Julio De Zan por haber llamado mi atención sobre este punto, aunque ignoro si he logrado convencerlo.

${ }^{18}$ Hannah Arendt, «On Violence», op. cit., p. 178. De hecho, Dante Alighieri cree que quien engaña merece un castigo mayor que quien actúa violentamente ya que el engaño es exclusivo de los seres que cuentan con razón y lenguaje. Ver: Prude Shaw, Reading Dante, Nueva York, Liveright Publishing, 2004, p. 155.

${ }^{19}$ Ver René Girard, «La Violence et le Sacré», en: De la Violence à la Divinité, Paris, Grasset, 2007, cap. 1.
} 
que pueden darse el lujo de invalidar tout court a las comunidades políticas por sus orígenes violentos. Sin embargo, un arendtiano insistiría en que una vez creada la comunidad, la relación entre violencia y política es excepcional, no constitutiva.

Sin duda, se trata de un argumento de raigambre aristotélica, tal como Arendt misma se encarga de señalar ${ }^{20}$. Después de todo, Aristóteles creía efectivamente que la política tenía un vínculo especial con el logos, el lenguaje. Sin embargo, habría que tener en cuenta que Aristóteles no por eso creía que la idea misma de la violencia política era contradictoria. En efecto, uno de los tópicos de la teoría política aristotélica es su discusión de la noción de virtud cívica o literalmente política, es decir, de las tareas que se espera que cumplan los ciudadanos o miembros de una polis ${ }^{21}$. Ahora bien, Aristóteles distingue entre tareas políticas "pacíficas» $y$ «bélicas» ${ }^{22}$, y es muy revelador que la primera tarea política que aparece en la lista de partes o clases de la polis ofrecida en Política IV.4 corresponda al género militar: to propolemèson, la clase que se ocupa de la defensa de la ciudad ${ }^{23}$.

Es digno de ser destacado además que si bien Aristóteles se opone terminantemente al militarismo, i.e. la doctrina según la cual la guerra debe ser la meta decisiva o preponderante de la comunidad política, entre otras cosas porque es incoherente tal como lo muestra el fracaso espartano ${ }^{24}$, sin embargo también cree que las muertes «más honrosas» o «más admirables moralmente» (kallistois) son las que tienen lugar en la guerra ${ }^{25}$ ya que la guerra es una ocasión para la virtud: mientras que «el goce de la buena fortuna y el descanso que acompaña a la paz nos vuelven más soberbios», «la guerra nos obliga a ser justos y sensatos» ${ }^{26}$. En líneas generales, entonces, Aristóteles entiende a la guerra como otros casos de violen-

${ }^{20}$ Ver Hannah Arendt, The Human Condition, Chicago, Chicago University Press, 1958, p. 27.

${ }^{21}$ Después de todo, un buen ciudadano es precisamente aquel que cumple adecuadamente con sus tareas cívicas.

22 Aristóteles, Política, 1254b31-32.

${ }^{23}$ El resto de la lista se refiere a quienes "participan en la administración de justicia», a «los que deliberan» acerca de los asuntos públicos, a «los ricos» 0 «los que cumplen con un servicio público por medio de su propiedad», y finalmente a «los servidores públicos, que sirven en conexión con las diferentes magistraturas» (Política 12919a7, 27-38, 33-34, 35).

${ }^{24}$ Ver Aristóteles, Política 1271b2-6 y 1334a6-9.

${ }^{25}$ Aristóteles, Ética a Nicómaco, 1115a30-31.

${ }^{26}$ Aristóteles, Política 1334a26-28. Las traducciones de la Política son nuestras, excepto las referencias hechas a Aristóteles, Política, trad. Carlos García Gual y Aurelio Pérez Jiménez, Madrid, Alianza, 1986, p. 297. 
cia justificada, i.e. como «correcciones y castigos justos» los cuales ciertamente "parten de la virtud, pero son necesarios y son moralmente admirables [to kalōs] por necesidad, (pues sería preferible) que no necesitara ninguna de esas cosas ni el hombre ni la ciudad $»^{27}$.

Vale recordar asimismo que en su discusión del régimen político ideal Aristóteles prevé tres razones que justifican el entrenamiento militar. La razón que inaugura el jus ad bellum o derecho aristotélico a la guerra es la de «evitar... ser esclavos de otros $»^{28}$. Una segunda razón es una guerra ofensiva de esclavización contra los que a juicio de Aristóteles merecen ser esclavos ${ }^{29}$. El motivo restante por el cual la mejor polis puede librar una guerra es el de «buscar la hegemonía, con el fin de beneficiar a los gobernados ${ }^{30}$. Esta justificación de la guerra nos remite ciertamente a la referencia a la «vida política» -en oposición a una vida puramente «teorética» o contemplativa- de la mejor polis, es decir, la vida de una polis con una robusta agenda internacional ${ }^{31}$, aunque fundamentalmente dentro del contexto griego (si se tratara del ámbito asiático entonces estaríamos por definición ante un caso de guerra de esclavización antes que de una guerra hegemónica).

Hay un segundo argumento de raigambre aristotélica que subyace a la posición arendtiana sobre la violencia política. En efecto, recordemos que según Arendt «Ninguna otra facultad excepto el lenguaje, ni la razón ni la consciencia, nos distingue tan radicalmente de todas las especies animales». Aquí Arendt evoca el célebre «argumento del ergon (función)», que para muchos subyace tanto a la teoría del bienestar aristotélico cuanto a la defensa aristotélica de la política. Como es sabido, Aristóteles sostiene que solamente los seres humanos cuentan con logos,

\footnotetext{
${ }^{27}$ Aristóteles, Política 1332a12-15, op. cit., p. 291, ligeramente modificada. Es digno de ser destacado, sin embargo, que la naturaleza moralmente admirable de la guerra según Aristóteles lo fuerza a sostener que los soldados no son sólo necesarios sino parte de la polis en sentido estricto (1326a20-21). ${ }^{28}$ Aristóteles, Política 1333b40-41.

${ }^{29}$ Aristóteles, Política 1334a2. En el cambio del orden de exposición de las justificaciones de la guerra seguimos a R. Meister, «Aristoteles als ethischer Beurteiler des Krieges», Neue Jahrbücher für Pädagogik, n 18, 1915, pp. 481-494.

${ }^{30}$ Aristóteles, Política 1333b41-34a 1 . Esta es una de las razones por las cuales el régimen ideal necesitará personal naval, marineros, etc. Ver Política 1327b1-15. Sobre Aristóteles y la virtud cívica ver Andrés Rosler, «Civic virtue: citizenship, ostracism, and war», en: Marguerite Deslauriers y Pierre Destrée (eds.), The Cambridge Companion to Aristotle's Politics, Cambridge, Cambridge University Press, 2013, pp. 144-175.

${ }^{31}$ Aristóteles, Política 1325a5-14; cf. 1265a18-25.
} 
lenguaje o razón ${ }^{32}$. Sin embargo, no queda del todo claro que Aristóteles emplee esta peculiaridad tal como varios de sus lectores lo han supuesto. En efecto, una interpretación bastante usual de la ética aristotélica cree que el bienestar humano deriva de un uso eficiente de la maximización de esta capacidad peculiar.

Ahora bien, creer que el valor de una capacidad (o de cualquier otra cosa para el caso) proviene del hecho de su peculiaridad es un caso de falacia de manual. Que algo sea peculiar, único, es exclusivamente un hecho, y de él muy poco se puede inferir acerca de su valor. Hay gente que tiene la capacidad de hurgarse la nariz a una velocidad asombrosa, sobre todo durante un semáforo en rojo. Sin embargo, de ahí no se sigue que dicho hábito sea valioso. Lo mismo se aplicaría si resultara que la especie humana es la única capaz de llevar a cabo semejante proceso. De hecho, como explicara Bernard Williams, si usáramos este criterio, creeríamos que es moralmente admirable «pasar el mayor tiempo posible haciendo fuego», «o teniendo sexo sin consideración de la estación, o depredando el medio ambiente y alterando el equilibrio de la naturaleza, o matando por placer $»^{33}$. Como también explica Cornelius Castoriadis, no debemos olvidar que si bien la especie humana «creó la razón, la libertad y la belleza, también creó la monstruosidad masiva. Ninguna especie animal jamás podría crear Auschwitz o el Gulag; para crear eso debes ser un ser humano» ${ }^{34}$. En rigor de verdad, si nos guiáramos por la peculiaridad, la violencia política bien podría ser lo que distingue a nuestra especie: la de actuar violentamente apelando a razones. Por lo demás, y por suerte para Aristóteles, él tampoco apuesta exclusivamente al argumento de la función para sustentar su teoría del bienestar ${ }^{35}$.

Finalmente, el rechazo arendtiano de la violencia política probablemente se deba también a cierta estetización de la política en la que parece incurrir Arendt. En efecto, dado que para Arendt la política es un fin en sí mismo ${ }^{36}$, la violencia, que es siempre un medio para un fin, no puede ser de naturaleza política. Sin

\footnotetext{
32 Aristóteles, Ética a Nicómaco 1097b24-1098ª18.

${ }^{33}$ Bernard Williams, Morality. An introduction to ethics, Cambridge, Cambridge University Press, 1993, p. 59.

${ }^{34}$ Cornelius Castoriadis, Philosophy, Politics, Autonomy. Essays in Political Philosophy, ed. David Ames Curtis, Nueva York, Oxford University Press, 1991, p. 88.

${ }^{35}$ Ver Stephen Everson, «Aristotle on nature and value», en: Stephen Everson (ed.), Ethics, Cambridge, Cambridge University Press, 1998.

${ }^{36}$ Ver Hannah Arendt, The Human Condition, op. cit., cap. 5.
} 
embargo, aunque Arendt tiene ciertamente razón acerca del carácter instrumental de la violencia, no todos comparten la estetización arendtiana de la política. En realidad, la política, por valiosa que fuera, además y fundamentalmente debe alcanzar ciertas metas, sin las cuales sería una actividad absurda o en todo caso puramente expresiva ${ }^{37}$.

En resumidas cuentas, la crítica arendtiana a la noción de violencia política tiene sentido en términos normativos, pero no conceptuales. Es ciertamente deseable que la violencia política quede reducida al mínimo indispensable. Pero de ahí no se sigue que sea contradictoria.

\section{LA TESIS LIBERAL}

Habiendo visto que la violencia criminal y la violencia política son nociones distintas y que la violencia política no es necesariamente una contradicción en sus términos, es hora de explorar el espacio lógico que existe entre la violencia común y la política, fundamentalmente cuál debe ser nuestra reacción moral al respecto. $\mathrm{Si}$ es que se trata de nociones distintas, ¿deben ser acaso tratadas de modo diferente? Y si así fuera, ¿¿cuál es mejor (o peor para el caso)?

A pesar del monopolio del uso legítimo de la fuerza con el que cuenta el Estado moderno desde sus inicios, el Estado de Derecho liberal adoptó la tesis que vamos a llamar precisamente «liberal», cuyo apogeo tuvo lugar a mediados del siglo XIX pero que se mantiene por lo menos hasta el fin de siglo, según la cual la violencia política es moralmente menos disvaliosa que la violencia criminal. Semejante apreciación moral se refleja en el tratamiento otorgado al delito político en términos de no extradición, asilo, privilegios legales del acto de guerra, qué decir de un eventual reconocimiento patriótico. Es indudable que los trastornos políticos ocasionados por la Revolución francesa explican en gran parte la necesidad de crear la figura del delito político concediéndole autonomía normativa y de ese modo proteger al orden jurídico.

Tal como lo sostiene un especialista en violencia política como Georges Sorel, «el crimen político es un acto de simple rebelión, que no puede entrañar infamia

37 Jon Elster, Sour Grapes. Studies in the Subversion of Rationality, Cambridge, Cambridge University Press, pp. 98-99. Cfr. Rüdiger Bubner, Antike Themen und ihre moderne Verwandlung, Frankfurt a.M., Suhrkamp, 1992, p. 199. 
alguna (...) ya no merece el nombre de crimen, porque su autor en nada se parece a los criminales» ${ }^{38}$. La manera misma en que el liberalismo abordaba la noción de delito político evoca el uso que la tradición republicana clásica le daba a términos tales como "política» $\mathrm{y}$ «cognados». En efecto, una vez establecido el régimen democrático en la polis clásica, "político» $\mathrm{y}$ «cognados» fueron aplicados tanto al interés que los individuos mostraban en los asuntos públicos, cuanto a su participación, a tal punto que el gobierno mismo era entendido como una comunidad de ciudadanos. De ahí que la expresión se refiriera a aquello que era considerado común en contraposición a lo que era considerado privado, auto-interesado, egoísta, etc ${ }^{39}$. Era natural entonces que la teoría política clásica opusiera el gobierno tiránico a la política en general. En efecto, no era infrecuente que la mera atribución de rasgos políticos a un diseño institucional expresara una evaluación moral subyacente y favorable de los mismos, y que la falta de vocabulario político en la descripción de otro diseño institucional expresara la inmoralidad del mismo ${ }^{40}$.

La tesis liberal del delito político descansa asimismo sobre una concepción epistémica de la política y del derecho. Para el liberalismo el orden político apunta a un consenso que debe ser el resultado de un intercambio de visiones y opiniones consideradas. La búsqueda de una respuesta correcta nos hace ser conscientes de que nos podemos equivocar, de que la otra parte puede tener razón y por lo tanto debemos mantener abiertas nuestras opciones, incluso si semejante actitud compromete al orden político mismo. Y de ahí que los liberales al entender a la política como una búsqueda de la verdad entre competidores en paridad de condiciones estén dispuestos no solamente a ponerle límites al poder ${ }^{41}$, sino a reconocerle status político incluso a quienes ocasionalmente optan por la violencia

38 Georges Sorel, Reflexiones sobre la violencia, op. cit., p. 162.

39 Ver Christian Meier, Die Entstehung des Politischen bei den Griechen, Frankfurt, Suhrkamp, 1983, p. 27.

${ }^{40}$ Ver Andrés Rosler, Political Authority and Obligation in Aristotle, Oxford, Oxford University Press, 2005, pp. 32, 240-242.

${ }^{41}$ El siguiente pasaje es revelador: «El error de los que, de buena fe en su amor por la libertad, han acordado a la soberanía del pueblo un poder sin límites, proviene de la manera en la cual se han formado sus ideas en política. Ellos han visto en la historia un pequeño número de hombres, o incluso uno solo, en posesión de un poder inmenso, que hacía mucho mal; pero su ira está dirigida contra los poseedores del poder y no contra el poder mismo. En lugar de destruirlo, ellos no han pensando en más que desplazarlo. Era una peste, pero ellos lo han considerado como una conquista» (Benjamin Constant, Écrits politiques, ed. Marcel Gauchet, Paris, Gallimard, 1997, p. 312). 
para hacer sus reclamos políticos, dado que hasta un enemigo vencido puede tener razón. Irónicamente, un destacado pensador anti-liberal como De Maistre es el que nos permite entender el corazón de la tesis liberal: «El que tuviera el derecho de decirle al Papa que está equivocado, tendría, por la misma razón, el derecho a desobedecerlo» ${ }^{42}$.

Hay cinco grandes aspectos de la tesis liberal que merecen ser destacados. En primer lugar, quien comete un acto de violencia política, según esta visión, es entendido como:

«un hombre de progreso, deseoso de mejorar las instituciones políticas de su país, teniendo intenciones loables, apresurando la marcha adelantándose a la humanidad, cuya única culpa es de querer ir demasiado rápido y de emplear, para realizar los progresos que él ambiciona, medios irregulares, ilegales y violentos» ${ }^{43}$.

En segundo lugar, para la tesis liberal el delito político es mala prohibita ${ }^{44}$. Por un lado, se trata de la relatividad espacial de la noción de enemigo según la cual lo que caracteriza a un buen ciudadano de un régimen podría considerarse enemistad declarada en otro régimen: el enemigo de una nación no tiene por qué ser el enemigo del género humano y un traidor a un país puede ser un excelente ciudadano en otro. Por el otro, se trata de la relatividad temporal. Guizot, por ejemplo, advertía que:

«Apenas se encontrará en la esfera de la política algún acto inocente o meritorio que no haya recibido, en algún rincón del mundo o del tiempo, una incriminación legal. (...). En cosas tan móviles, tan complicadas, la verdadera moralidad de las acciones no se deja así determinar absolutamente ni aprisionar para siempre en el texto de las leyes.... ${ }^{45}$.

\footnotetext{
42 Joseph De Maistre, Du Pape, Paris, 1841, p. 6.

${ }^{43}$ Georges Vidal, Cours de droit criminel et de science pénitentiaire, Paris, A. Rousseau, 1901, p. 101. Ver Sophie Dreyfus, Généalogie du délit politique, Paris, Foundation de Varenne, 2009, pp. $353,359,360-361$ y 366.

${ }^{44}$ Como explica Joseph Viaud, La peine de mort en matiére politique, Paris, Arthur Rousseau Éditeur, 1902, p. 14: «Lo que la ley positiva llama un crimen político no es siempre una falta en moral».

${ }^{45}$ François Guizot, Des conspirations et de la justicie politique. De la peine de mort en matière politique, Paris, Fayard, 1984, pp. 117-118. La tesis de Guizot sobre la relatividad temporal del delito político fue confirmada por lo que hoy sabemos sobre la huelga, la cual dejó de ser un grave acto
} 
En tercer lugar, una típica distinción liberal como lo es la separación conceptual entre la sociedad y el Estado (y/o el gobierno) explica que el enemigo del gobierno no es necesariamente un enemigo del Estado y/o de la sociedad ${ }^{46}$. Lentamente, lo político deja de ser monopolio del Estado y termina cobrando vida propia, por así decir. Este fenómeno está estrechamente vinculado con la separación moderna entre la razón (u opinión) pública y la razón (u opinión) de Estado. En efecto, mientras que, por ejemplo, Montaigne y Hobbes todavía creían que la opinión pública era la del Estado, en el siglo XVIII la opinión pública corresponde a la de la sociedad civil entendida como una esfera intermedia entre el sector privado y el Estado ${ }^{47}$, fenómeno que ya es perceptible a comienzos del siglo XVII en el Julio César de Shakespeare, en el cual la conexión entre la esfera pública y el delito político salta a la vista. En efecto, la expresión «razón pública» muestra no sólo la aspiración principista de todo delito político, sino que además indica la ambigüedad de la expresión justo en ocasión del pasaje de su connotación estatal a la burguesa por así decir: se trata de razones públicas porque atañen al Estado y además porque serán ofrecidas a la esfera pública ${ }^{48}$.

En cuarto lugar, tal como lo sostiene hacia 1875 el penalista francés Joseph Ortolan, «la pena del delito político tendrá siempre en su principio alguna cosa de las medidas que se aplican a un enemigo: el legislador penal... no debe perder de vista este carácter ${ }^{49}$. El enemigo al que se refiere el paradigma liberal francés, sin embargo, no es el de la guerra justa invocada por Saint-Just contra Luis XVI, sino el enemigo regular del derecho público europeo, que con el tiempo permitió que incluso quienes combatieran en una guerra civil quedaran comprendidos dentro del régimen de beligerancia ${ }^{50}$. El acto del delincuente ideológico o político entonces merecería el mismo grado de autonomía normativa concedido al acto de guerra.

violento y, por eso, un delito que afectaba sustancialmente derechos constitucionales básicos como la libertad de comercio y la propiedad privada para convertirse en un derecho constitucional imprescindible. ${ }^{46}$ Ver Sophie Dreyfus, Généalogie du délit politique, op. cit., p. 272. «Un enemigo del poder no era... un enemigo del género humano, ni siquiera de la Nación» (Joseph Viaud, La peine de mort en matiére politique, op. cit., pp. 210-211).

47 Ver Jürgen Habermas, Strukturwandel der Öffentlichkeit. Untersuchungen zu einer Kategorie der bürgerlichen Gesellschaft, Frankfurt, Suhrkamp, 1990, pp. 162-163; Reinhart Koselleck, Kritik und Krise. Eine Studie zur Pathogenese der bürgerlichen Welt, Frankfurt, Suhrkamp, 1973, p. 44.

48 William Shakespeare, Julius Caesar, op. cit., III.ii.8.

49 Joseph Ortolan, Éléments de droit penal, Paris, Plon, 1875, p. 707 (énfasis agregado).

${ }^{50}$ Ver Carl Schmitt, Der Nomos der Erde, Berlin, Duncker \& Humblot, 1950, pp. 274, 275 y 278. 
En quinto lugar, vae victis! o la causa victoriosa complace a los dioses ${ }^{51}$. En efecto, la otra cara de reconocer que detrás del delincuente político hay un enemigo -aunque, insistimos, no el injusto o irregular sino el relativo o justo del derecho público europeo- es reconocer que la performatividad tiene mucho que ver con la distinción entre delincuente político y un patriota. Otro penalista como Georges Vidal señalaba en este sentido que «el autor de un crimen político, que es un vencido más que un criminal, puede devenir, como resultado de una revolución favorable a sus ideas, el vencedor de mañana llamado a la dirección regular del Estado y a la administración pública de su país»" ${ }^{52}$. Sorel advertía exactamente lo mismo, aunque ciertamente con otros fines: «el criminal de hoy puede pasar a ser el juez de mańana " ${ }^{53}$. Menáchem Begin y Yasser Arafat son ejemplos de cómo incluso hasta los terroristas pueden convertirse en estadistas si es que la fortuna les sonríe.

\section{LA TESIS SOBERANA}

Hablando de terrorismo, es hora de señalar que la tesis liberal es mucho menos liberal de lo que parece, ya que para los liberales no cualquier tipo de violencia principista calificaba como delito político en el sentido jurídico del término. En efecto, los mismos liberales que suscribían la superioridad moral del delito principista, no solamente distinguían entre delito común y el político, sino también entre el delito político y lo que llamaron «delitos anti-sociales», o si se quiere, entre principios o ideologías correctas e incorrectas. Juristas como Franz Lieber, que creían representar a la conciencia legal o jurídica del mundo civilizado, defendían el voto universal, el constitucionalismo social y el Estado de Derecho, no dudaron sin embargo en apelar a «la represión para defender su liberalismo aristocrático» frente a los desafíos ocasionados por el anarquismo ${ }^{54}$. En 1869, por otro lado, Fedor Martens, el famoso profesor y diplomático ruso-báltico, argumentaba en el

\footnotetext{
51 «Nosotros celebramos hoy por una fiesta nacional la toma de la Bastilla. Si alguno hoy intentara el asalto de una Bastilla moderna no solamente no sería glorificado sino tratado como faccioso, y las razones de esta diferencia serían tan netas que el poder no imaginaría la posibilidad de reproche alguno» (Joseph Viaud, La peine de mort en matiére politique, op. cit., p. 42).

52 Georges Vidal, Cours de droit criminel et de science pénitentiaire, op. cit., p. 103.

${ }^{53}$ Georges Sorel, Reflexiones sobre la violencia, op. cit., p. 154.

54 «Lo que hoy pasa por anarquista no lo será mañana» (Joseph Viaud, La peine de mort en matiére politique, op. cit., p. 423).
} 
Institut de Droit International que los tiempos habían cambiado. Mientras que el número de refugiados políticos «reales» había disminuido, el número de «criminales» políticos se había incrementado, y por esto último entendía: miembros de la Comuna, nihilistas, socialistas, todos los que a través del homicidio y del incendio provocado o estrago buscaban la anarquía y celebraban los «instintos bestiales del hombres" ${ }^{55}$.

En este mismo sentido en 1879 el Institut de Droit International adoptó una resolución según la cual los Estados podían ejercer jurisdicción penal extraterritorial en caso de actos cometidos en cualquier lado por cualquiera, si tales actos eran ataques en contra de «la existencia social del Estado» o ponían en peligro su seguridad. Actos inspirados por el anarquismo y el comunismo constituían entonces crímenes contra todos los Estados, aunque al año siguiente el Instituto se expresó a favor de la denegación de extradición en caso de delitos políticos para el caso de actividades que no configuraran delitos comunes.

De ahí que los mismos liberales creían que cuando, en las palabras de Kant, «la violencia, con la frente bien alta y siguiendo principios, se eleva sobre el derecho más sagrado», se trataba de un «un delito sin expiación posible»" ${ }^{56}$. Esta nueva manera de entender y por supuesto de agravar al menos ciertos casos de violencia política podemos designarla como «soberana».

Ciertamente, la persecución de la que fueron objeto, v.g., los anarquistas luego de la Comuna de París muestra que la decisión que distingue entre el delito político y los delitos «anti-sociales», así como la que separa al delito político del común, es una decisión política en sí misma, lo cual está lejos de ser sorprendente. Sin embargo, quizás sea más fácil simpatizar con la tesis soberana una vez que advertimos que no todo principismo o idealismo es por definición moralmente superior al auto-interés.

En efecto, Hannah Arendt nos recuerda que Eichmann mismo se consideraba un idealista, i.e. alguien que ciertamente «no robaba o aceptaba sobornos» pero fundamentalmente «vivía por su idea (...) y que estaba preparado para sacrificar por esta idea todo y, especialmente, a todos». Es más, cuando Eichmann:

55 V. Martti Koskenniemi, The Gentle Civilizer of Nations. The Rise and Fall of International Law 1870-1960, Cambridge, Cambridge University Press, 2001, p. 69.

${ }^{56}$ Immanuel Kant, Metafísica de las costumbres, op. cit., p. 154. 
«dijo en la investigación policial que él habría enviado a su propio padre a la muerte si le hubiese sido requerido, no solamente quiso meramente enfatizar el extremo hasta el cual él estaba bajo órdenes, y listo para obedecerlas; él también quiso mostrar qué ¿idealista había sido siempre» ${ }^{57}$.

Algunos, seguramente no sin razón, han puesto en cuestión esta auto-comprensión de Eichmann, demasiado conveniente para decir lo menos. Sin embargo, el punto que le interesaba a Arendt era cómo explicar la irracionalidad de la conducta nazi de destinar semejante cantidad de recursos en medio de una guerra mundial a la comisión de un genocidio. La tesis principista es ciertamente una explicación ${ }^{58}$.

El discurso de los derechos humanos ha restringido severamente el antiguo régimen del delito político deliberadamente para impedir que el terrorismo, un típico fenómeno de criminalidad ideológica, disfrutara del status privilegiado del delito político. En efecto, la tesis soberana cree entonces que la violencia política es una infracción mala in se y tiene una larga prosapia ${ }^{59}$. Este rechazo del principismo es constitutivo de la tesis soberana, la cual a su vez contiene ciertos rasgos de naturaleza teológico-política. En efecto, como sostiene Pierre Manent, también ha señalado la estructura teológica de los delitos de lesa humanidad:

«En el antiguo orden, el crimen más grave e imperdonable era el sacrilegio -el crimen contra Dios, o las cosas consideradas sacras, que incluían el regicidio y el parricidio. En el nuevo orden democrático, el crimen más grave, el crimen para el cual no hay prescripción de la acción, es el crimen contra la humanidad ${ }^{60}$.

En realidad, no es exactamente una novedad que «en la decapitación revolucionaria del «último» rey [pudo verse] un dispositivo simbólico todavía interno a la

\footnotetext{
57 Hannah Arendt, Eichmann in Jerusalem, Londres, Penguin, 2006, p. 39.

58 «Es muy desafortunado que, a los ojos de muchos, un ‘elemento auto-sacrificials es la mejor prueba de intensidad de preocupación (...), ya que el fanatismo resoluto es usualmente la marca del chiflado y, en todo caso, hace imposible una discusión racional de los tópicos en cuestión» (Hannah Arendt, "Civil disobedience», en: Crises of the Republic, op. cit., p. 66).

59 Ver Franceso Carrara, Programma del corso di diritto criminale, Firenze, Lucca, 1870, vol. VII, § 3917. ${ }^{60}$ Pierre Manent, $A$ World beyond Politics. A Defense of the Nation-State, Chicago, Chicago University Press, 2006, p. 124.
} 
lógica de la soberanía e inclusive funcional a su reproducción potenciada: $E l$ dar muerte al rey es la mayor afirmación de la soberania ${ }^{61}$. Da la impresión entonces de que Su Majestad, la Humanidad, ha ocupado el lugar de la antigua soberanía, tal como lo muestra de hecho el reemplazo de la antigua expresión crimen de lesa majestad por la expresión algo reciente de crimen de lesa humanidad, al menos en los idiomas que derivan del latín. Pero la cuestión no es puramente históricoconceptual, sino que uno de los problemas que parece traer aparejado el empleo de la tesis soberana es su propensión a cierto explosivo cocktail cuyos ingredientes son un derecho aplicable controversial, una oscilación del status normativo de la violencia ilegal entre crimen y guerra, y finalmente una sinécdoque universalista ${ }^{62}$.

En efecto, repasemos la emergencia moderna de la tesis soberana. Si bien los revolucionarios franceses eran abolicionistas capitales, hacían una excepción para el caso de los delitos políticos ${ }^{63}$. Muchos diputados, el más conocido de los cuales era Robespierre, creían que aunque la pena capital no debía tener lugar en la sociedad civil, Luis XVI presentaba una «cruel excepción a las leyes ordinarias» y que era «el único que podía (...) recibir legítimamente» la pena de muerte. Nicolas-Marie Quinette, miembro de la Convención, el 6 de diciembre de 1792 sacó claramente a la luz la naturaleza agravante de los delitos políticos: «Estoy de acuerdo con los que piensan que este castigo debe ser borrado de nuestra legislación civil; pero demostraré en el futuro que debe ser reservado para crímenes políticos, o aquellos que buscan destruir la libertad $»^{64}$.

${ }^{61}$ Georges Bataille, «La sovranità», citado por Roberto Esposito, Diez pensamientos acerca de la política, Buenos Aires, Fondo de Cultura Económica, 2012, p. 114.

62 Es bastante irónico que el terrorismo (o mejor dicho el «terror», ya que «terrorismo» es una expresión termidoriana) haya sido una creación del discurso soberano revolucionario y que haya sido no sólo estatal sino legal. Ver Sophie Wahnich, In Defence of the Terror. Liberty or Death in the French Revolution, Londres, Verso, 2012, pp. 48-49 y 64-65.

${ }^{63}$ Habría que tener en cuenta que «La noción de lesa-majestad fue (...) vivamente criticada al comienzo de la Revolución como constituyendo un concepto incriminante demasiado vago, sinónimo de arbitrario. Los Constituyentes de 1791 hacen desaparecer este concepto para sustituirlo por definiciones precisas y rigurosas, a fin de volver teóricamente imposible toda arbitrariedad en la represión judicial» (Sophie Dreyfus, Généalogie du délit politique, op. cit., p. 96). Sin embargo, no tardaron en tipificar el «crimen de lesa-nación», cuyo conocimiento corresponde a una Alta Corte nacional y la acusación al Cuerpo legislativo, según la Constitución de 1791 (Ídem, p. 131).

${ }^{64}$ Citado en Dan Edelstein, The Terror of Natural Right. Republicanism, the Cult of Nature and the French Revolution, Chicago, Chicago University Press, 2009, p. 151, n. 97. 
La gravedad del crimen tenía dramáticas repercusiones procesales, tal como nos lo recuerda Sorel:

«Los procesos contra los enemigos del rey fueron siempre llevados de manera excepcional; se simplificaban los procedimientos todo lo posible; se daban por suficientes pruebas mediocres, que no hubieran bastado para los delitos ordinarios; se trataba de infligir castigos ejemplares y que intimidasen profundamente».

Sorel enfatiza que monárquicos y republicanos convergieron en este punto, ya que lo mismo ocurrió durante la revolución:

«La ley del 22 de pradial se contenta con definiciones un tanto difusas del crimen político, con el fin de de no dejar escapatoria a ningún enemigo de la Revolución; y, en lo que a pruebas respecta, son dignas de la más pura tradición del Antiguo Régimen y de la Inquisición. La prueba necesaria para condenar a los enemigos del pueblo es cualquier clase de documento, ya sea material, moral, verbal o escrito, que de modo natural puede lograr el asentimiento de toda persona justa y razonable. La regla de los juicios es la conciencia de los jurados iluminados por el amor a la patria; su objetivo es el triunfo de la República y la derrota de sus enemigos»" ${ }^{65}$.

Veamos ahora un poco más detalladamente los ingredientes del cocktail soberano revolucionario. En primer lugar, el derecho aplicable. Dado que Luis XVI gozaba de inviolabilidad constitucional desde septiembre de 1791, durante su juicio fue invocado el derecho natural o de gentes para poder acusarlo y condenarlo. Por ejemplo, según Saint-Just, el rey debía «ser juzgado como enemigo (...) nosotros tenemos menos que juzgarlo que combatirlo y (...) no estando más en el contrato que une a los franceses, las formas del procedimiento no están en absoluto en la ley civil, sino en la ley del derecho de gentes ${ }^{66}$.

En segundo lugar, la naturaleza jurídica de la conducta violenta de la que fue acusado Luis XVI como tirano osciló entre un crimen y un acto bélico. Por un lado, la conducta de Luis XVI era considerada criminal. Saint-Just, en efecto, expresaba su preocupación de que en el futuro los seres humanos «se asombrarán de

65 Georges Sorel, Reflexiones sobre la violencia, op. cit., p. 161 (destacado en el original).

${ }^{66}$ Saint-Just, CEuvres complètes, Paris, Gallimard, 2004, p. 476. 
la barbarie de un siglo en el cual tenía algo de religioso juzgar un tirano, cuando el pueblo que tenía un tirano para juzgar lo eleva al rango de ciudadano antes de examinar sus crímenes». Saint-Just advertía entonces que:

«Se sorprenderán un día que en el siglo dieciocho se haya avanzado menos que desde los tiempos de César: allí el tirano fue inmolado en pleno Senado, sin otras formalidades que veinticuatro puñaladas, y sin otra ley que la libertad de Roma. ¡Y hoy se hace con respeto el proceso de un hombre asesino de un pueblo, capturado en flagrante delito, la mano en la sangre, la mano en el crimen! ${ }^{67}$.

No es de extrañar entonces que a Luis XVI le cabe la distinción de haber sido quizás el primer «criminal en contra de la humanidad», tal como lo describiera Robespierre.

Pero, por el otro lado, el hecho mencionado por Saint-Just según el cual no tenía sentido llevar a juicio al rey ya que se trataba de un enemigo que debía ser, sin más, muerto en el senado, implica que para él la cuestión no era de derecho penal sino bélica en realidad, algo así como un «derecho penal del enemigo». Obviamente, el sentido de tratar criminales como enemigos es que elimina la burocracia del procedimiento penal de tal forma que quienes desobedecen la autoridad del Estado pueden ser tratados de manera más expeditiva. No hace falta acusación, juicio, audiencias; pueden ser capturados o detenidos meramente por su pertenencia a un grupo, no hace falta evaluar la responsabilidad individual; los enemigos son juzgados -si es que lo son en absoluto-según los estándares bastante más relajados del derecho natural en comparación con el derecho positivo, y de hecho no hace falta acción alguna por parte del autor del hecho para poner en marcha el dispositivo estatal sino sólo la capacidad de dañar al Estado.

En tercer lugar, la sinécdoque. En efecto, la concepción revolucionaria de la tesis soberana no sólo cree que al rey se le debe aplicar el derecho natural y que es un criminal en contra de o un enemigo de la revolución y/o del pueblo francés sino que además es un criminal contra o enemigo de la humanidad en general. El rey es puesto en compañía de tiranos, salvajes, forajidos, piratas y demás hostes humani generis ${ }^{68}$.

67 Ibidem.

${ }^{68}$ Dan Edelstein, The Terror of Natural Right, op. cit., p. 18. 


\section{TERRORISMO}

Hasta aquí hemos estado hablando de terrorismo de un modo bastante laxo, así que es hora de precisar la noción. En efecto, la definición contemporánea estándar del terrorismo es tan moralizante que el intento de discutir la moralidad de un acto terrorista lisa y llanamente es un sinsentido. Si bien la definición de todo concepto cultural alberga ingredientes valorativos, en el caso del terrorismo la definición usual parece ser parte de una campaña antes que una ayuda para pensar ${ }^{69}$.

Para evitar al menos algunas de estas dificultades, convendría seguir los pasos de quienes en los últimos años recomiendan dejar de entender al terrorismo como una ideología necesariamente perversa -o qué decir como una patología psicológica- para entenderlo como una forma de violencia política, i.e. como el ataque deliberado contra no combatientes, con independencia de quiénes sean los que realizan el acto (insurgentes o estatales) y de cuáles sean los fines que inspiran dicho acto (principios o ideologías de izquierda o de derecha, o insurgentes o estatales) ${ }^{70}$.

Ciertamente, mi punto no es que el terrorismo contemporáneo es sólo una creación estatal mediante la cual el enemigo es criminalizado -o al revés, como parece suceder en nuestro país, que el terrorismo de Estado es una expresión redundante- sino que la manera soberana en que solemos entenderlo contribuye a que la noción sea fácil presa de la moralización y al cocktail explosivo detallado más arriba: se trata de una noción jurídicamente inestable, que oscila entre el delito y la guerra, y que además atenta contra la Humanidad.

En realidad, quienes comparten la caracterización instrumental o táctica del terrorismo no están de acuerdo acerca de si el terrorismo es necesariamente injustificable o inexcusable. Por ejemplo, Tony Coady adopta esta caracterización táctica o instrumental del terrorismo pero sostiene que el terrorismo es injustificable en todo sentido debido a que suscribe una versión de la doctrina del doble efecto, según la cual nunca puede estar justificado el ataque deliberado contra

${ }^{69}$ Cecil A. J. Coady, Morality and Political Violence, op. cit., p. 155.

70 Aunque el terrorismo que nos interesa es el político, si es que no se trata de una expresión redundante. Sobre la naturaleza principista del terrorismo, ver Günther Jakobs, «Bürgerstrafrecht und Feindstrafrecht», hrr-strafrecht.de, Online-Zeitschrift HRRS \& Rechtsprechungsdatenbank, $\mathrm{n}^{\circ} 3$, 2004, pp. 90-95, disponible en: www.hrr-strafrecht.de/hrr/archiv/04-03/index.php3?seite=6 (último ingreso: 05/12/2014); y Sophie Dreyfus, Généalogie du délit politique, op. cit., pp. 281, 422 y 467). 
no combatientes, sino sólo aquello que fuera un efecto colateral, esto es, previsto pero no deseado, de un acto moralmente bueno de modo inherente y que no sea querido ni como meta ni como medio de la acción ${ }^{71}$.

Ahora bien, la aproximación puramente instrumental del terrorismo no sólo impide, v.g., que la expresión terrorismo de Estado sea redundante, sino que además abre la puerta a la posibilidad de que un acto terrorista sea, si no justificable, quizás al menos excusable ${ }^{72}$. En efecto, Uwe Steinhoff, por ejemplo, toma el camino instrumental y por eso sostiene que la valoración del terrorismo dependerá de muchos factores. Steinhoff critica la doctrina del doble efecto, ya que cree que en lugar de ser un medio eficaz para proteger los derechos de las víctimas de los actos de doble efecto no es sino un tranquilizante para las consciencias de los que violan tales derechos. Para Steinhoff, los derechos de las víctimas son igualmente violados tanto en casos de muertes colaterales como en el caso de muertes deliberadas o directas, provocadas fundamentalmente por los actos de guerra realizados por los Estados ${ }^{73}$.

Para ilustrar la crítica de Steinhoff a la doctrina del doble efecto podemos usar el ejemplo de Philippa Foot que él mismo utiliza y que pertenece a la familia de casos de la amenaza inocente. Al salir en una expedición espeleológica, un hombre obeso se queda atascado en una abertura, bloqueando la salida de los demás miembros de la expedición. Desafortunadamente, el nivel de agua en la caverna empieza a subir, de tal forma que todos morirán si no pueden despejar la abertura. La única posibilidad es usar dinamita, que justo tenía uno de los expedicionarios, y volar al hombre obeso. Foot sostiene que sería absurdo si los espeleólogos argumentaran que la muerte del obeso sería sólo una consecuencia previsible de la explosión y por lo tanto afirmaran: «No quisimos matarlo (...) sólo volarlo en pequeńos pedazos» ${ }^{74}$. Nos recuerda a lo que lamenta Bruto en la noche anterior a

\footnotetext{
71 Ver Cecil A. J. Coady, op. cit., p. 159.

72 Buchez y Roux-Lavergne creen que «el terror no es (...) ni un medio para reprobar de manera absoluta, ni un medio para emplear para todo propósito y sin cálculo. Es un método, y como todo método, es por su meta que se lo juzga». Histoire parlementaire de la Révolution française ou journal des assemblées nationales depuis 1789 jusqu'en 1815, Paris, t. XX, pp. v-vi, cit. en: Mario Turchetti, Tyrannie et tyrannicide de l'Antiquité á nos jours, op. cit., p. 718.

73 Uwe Steinhoff, On the Ethics of War and Terrorism, Oxford, Oxford University Press, 2007.

74 Ídem, p. 39.
} 
la conspiración contra César: «Oh, si (...) pudiéramos llegar al espíritu de César y no desmembrar a César! Pero, lamentablemente, César debe sangrar por eso ${ }^{75}$.

Steinhoff sostiene que de hecho la diferencia entre guerra y terrorismo no debería ser estipulativa, sino que debe residir «en las dimensiones y adecuación del ataque» ${ }^{76}$. Como resultado, si algunos actos como el bombardeo estatal de no combatientes, desde Dresden hasta las últimas campañas en Medio Oriente o en Irak, están justificados, «no es del todo claro por qué el ataque al World Trade Center no debería estar justificado» ${ }^{77}$. En todo caso, todas las fichas de la teoría de la guerra justa o estatal están puestas en la doctrina del doble efecto, lo cual es una apuesta muy riesgosa tal como hemos visto. Después de todo, la guerra estatal provoca un número de víctimas considerablemente superior al de los actos terroristas.

Michael Walzer, por su parte, un muy prestigioso defensor de la teoría de la guerra justa estatal, cree que el terrorismo es claramente inmoral. Pero también cree que en caso de una «emergencia suprema», i.e., cuando «nuestros valores más profundos y nuestra supervivencia colectiva están en peligro inminente ${ }^{78}$, no hay otra alternativa razonable que actuar de modo inmoral ${ }^{79}$. Para ser más precisos, según Walzer «el terrorismo estaría justificado en una emergencia suprema», "solamente si la opresión a la cual los terroristas pretenden estar respondiendo era genocida en carácter». Permítaseme ilustrar la posición de Walzer ${ }^{80}$. Supongamos que tiene lugar un encuentro de culturas similar al ocurrido entre Europa y América a comienzos del siglo XVI, y que la única manera de evitar un genocidio resultante fuera raptar los hijos del conquistador, suponiendo que dichos hijos fueran no combatientes. Pues bien, quizás el daño deliberado contra dichos no combatientes sería el único medio para prevenir el genocidio, lo cual ilustra el punto de Walzer. Sin embargo, no debemos olvidar que si bien:

\footnotetext{
75 William Shakespeare, Julius Caesar, op. cit., Il.i.169-71.

${ }^{76}$ Uwe Steinhoff, op. cit., p. 124. Como también afirma Karl Heinzen: «Si nosotros queremos el fin, entonces debemos querer los medios; si queremos la vida de los pueblos, entonces deben querer la muerte de sus enemigos; si queremos la Humanidad, entonces debemos querer el homicidio/asesinato [Mord]». Karl Heinzen, Mord und Freiheit, s/d, 1853, p. 36.

77 Uwe Steinhoff, op. cit., p. 124.

78 Michael Walzer, Arguing about war, New Haven, Yale University Press, 2004, p. 33.

$79 \mathrm{O}$ quizás siguiendo una moralidad de segundo orden.

${ }^{80}$ Se trata de un ejemplo inspirado en Uwe Steinhoff, op. cit., p. 133.
} 
«Contra la amenaza inminente de extinción política y física, medidas extremas pueden ser defendidas, asumiendo que tengan alguna chance de éxito. Pero esta clase de amenaza no ha estado presente en ninguno de los casos recientes de actividad terrorista. El terrorismo no ha sido un medio para evitar un desastre sino de alcanzar éxito político» ${ }^{81}$.

\section{LIBERTAD Y CIENCIAS HUMANAS}

Una conclusión que podemos extraer es que si el terrorismo es una metodología no tiene sentido hacerle una guerra, ya que la guerra es librada contra ciertos agentes, no contra estrategias en sí mismas. Además, la idea de guerra supone cierta simetría normativa entre los combatientes, mientras que el terrorismo es entendido claramente como un crimen, un súper-crimen en realidad, en el cual la asimetría de todo crimen se ve particularmente acentuada.

Otra de las consecuencias de la naturaleza criminal del terrorismo es que la tesis según la cual los juicios del tipo «X pero Y», v.g. «la matanza de Charlie Hebdo es un crimen atroz e imperdonable, pero debe ser entendida en contexto», a pesar de que se trata de una tesis que todavía cuenta con no pocos adeptos, es redundante o seriamente contraproducente. La pregunta es, en efecto, qué es lo que agrega el famoso «pero» en esta llamativa proposición. Por un lado, es obvio que toda acción, qué decir las criminales, deben ser puestas en contexto ya que es absurdo -o perversocondenar (o absolver para el caso) una acción sin haberla comprendido. Solamente la Policía de la Provincia de Buenos Aires, dicen, primero valora y después pregunta.

De ahí que surja la duda de si quienes usan la proposición «X pero Y» en estos casos quieren señalar un punto redundante. Una alternativa es la mera curiosidad, tal como Publio Escipión alguna vez le preguntara a sus tropas luego de que éstas hubieran cometido un acto nefasto de insubordinación: «yo, aunque ningún crimen tiene justificación [o literalmente 〈razón〉], sin embargo, en la medida en que sea posible en un hecho nefasto, querría saber cuál fue vuestra idea, vuestra intención ${ }^{82}$.

Ahora bien, el «pero» en cuestión parece ir mucho más allá de la redundancia y la curiosidad, ya que pretende hacer una diferencia real. La pregunta entonces

${ }^{81}$ Michael Walzer, op. cit., p. 54.

82 Tivo Livio, Ab Urbe Condita (Historia de Roma desde su fundación), XXVIII.28. Disponible en: http:// www.thelatinlibrary.com/livy/liv.28.shtml\#28 (último ingreso: 05/12/2014). 
es qué diferencia puede hacer este «pero». Lo que suele aparecer luego del pero es la referencia a la desigualdad social y económica, la exclusión, etc., de quienes cometieron el acto. Se trata de una actitud que no era extraña a los liberales franceses que se podría decir crearon la noción de delito político. Por ejemplo, un verdadero liberal como Constant invertía la carga de la prueba, ya que para Constant los verdaderos responsables de los delitos políticos -si es que Constant habría estado dispuesto a entender al terrorismo como un delito político- son la sociedad y el gobierno. La existencia de una conspiración prueba que «la organización política de un país en donde se urden estas conspiraciones es defectuosa». Constant creía ciertamente que dichas conspiraciones deben ser reprimidas:

«pero la sociedad no debe desplegar contra los crímenes de los que sus propios vicios son la causa sino la severidad indispensable; ya es lo suficientemente lamentable que ella esté forzada a castigar a hombres que, si ella estuviera mejor organizada, no habrían devenido culpables jamás» ${ }^{83}$.

Precisamente, la explicación que suele seguir al "pero» atenúa -si no es que exonera de- la responsabilidad de quienes cometieron la matanza. Si no hubieran sido víctimas de desigualdad y exclusión, los implicados jamás habrían cometido el acto. Pero entonces, el punto es que no fueron libres de actuar de otro modo. Se trata de una hipótesis con proyecciones muy preocupantes, amén de que empíricamente es bastante dudosa.

Ahora bien, aunque supusiéramos que fuera correcta, no haría falta ser un científico especializado en cohetes para darse cuenta de que no tendría sentido entonces repudiar el acto, ya que equivaldría a responsabilizar a quienes fueron víctimas de desigualdad y exclusión, las cuales los llevaron a cometer lo que parecía

${ }^{83}$ Benjamin Constant, Écrits politiques, op. cit., p. 580. La pregunta que nos debemos hacer ahora es si tiene sentido creer que la responsabilidad penal admite la noción de culpa concurrente, como sí sucede con la responsabilidad civil, como si alguien pudiera ser parcialmente culpable o inocente de un delito. Hasta donde sabemos, el único defensor de la responsabilidad parcial en materia penal, incluso en relación a un delito de lesa humanidad, es Hernán Brienza: «Nadie cree en su sano juicio que Milani [Jefe del Ejército argentino sospechado de haber cometido un delito de lesa humanidad] es absolutamente inocente. $Y$ tampoco nadie puede afirmar que Milani es absolutamente culpable» («El debate por Milani», Tiempo Argentino, 22/12/2013, disponible en: http://tiempo.infonews.com/ nota/72331/el-debate-por-milani). 
ser un crimen. Insistir con el repudio -y qué decir con un eventual castigo- no solamente sería contradictorio ${ }^{84}$, sino además completamente sádico.

Otro tanto sucedería con quien ofreciera la siguiente explicación evolutiva: "por supuesto, los asesinatos no son remotamente justificables. Sin embargo, esta violencia no es azarosa. Es el resultado de la combinación de religión extrema, ostracismo social, impulsos agresivos dirigidos por testosterona y jóvenes marginados. Se trata de una combinación letal». Otra vez, si las causas fueron tales, o en realidad si es que hubo causas en sentido estricto, los implicados no pudieron haber sido entonces héroes, pero tampoco responsables por lo que hicieron. Toda explicación posterior a la valoración hace caer el repudio, so pena de contradicción o sadismo.

Alguien podría decir que en realidad el modus operandi de las ciencias humanas tal como suelen ser practicadas hoy en día son un obstáculo para cualquier juicio moral, ya que su trabajo consiste precisamente en explicar y comprender todo acto humano y de esta forma diluir la libertad y por lo tanto la responsabilidad de los agentes en las causas que los determinan y/o en las culturas a las que pertenecen.

Sin duda, alguien podría objetar que hemos ido demasiado rápido. Después de todo, la explicación que hace hincapié en la desigualdad y en la exclusión es de naturaleza moral ya que semejantes fenómenos no son naturales como un terremoto o un huracán sino que se deben en última instancia a decisiones humanas.

Sin embargo, esta objeción en realidad refuerza nuestro punto. En efecto, nuestro rechazo de la desigualdad y de la exclusión se debe a que son evitables ya que son el producto de la explotación capitalista. ¿Podrían sin embargo los dueños de las grandes corporaciones multinacionales alegar que son capitalistas por razones culturales, o porque los educaron así, y por eso les resulta indiferente la pobreza global que ocasionan? Y los funcionarios del Departamento de Estado que ejecutan las órdenes de bombardear no combatientes y entrenar fanáticos que luego se les van de las manos -qué decir de quienes toman semejantes decisiones-, ¿podrían alegar con razón que lo hacen por razones igualmente culturales, porque los educaron para hacer eso, y por lo tanto no tiene sentido criticarlos? Si fuéramos consistentes en este caso deberíamos decir: «el capitalismo es atroz, pero...», con lo cual atenuaríamos o aniquilaríamos lo que parecía ser un rechazo moral. La proposición «X pero Y», entonces, de ser verdadera, debe ser aplicada en todos los

\footnotetext{
${ }^{84}$ Una contradicción que emerge claramente en la declaración del polemista francés Dieudonné, que reú-
} ne a las víctimas de la matanza con los autores del crimen, en su frase: «yo me siento Charlie Coulibaly». 
casos. Nuestra filosofía de las ciencias sociales, por así decir, no puede depender de nuestra ideología política.

Supongamos ahora, en aras de la argumentación, que hemos dado con instituciones sociales, políticas, culturales, etc., tales que en lugar de distorsionar nuestras capacidades racionales y morales por el contrario logran permitir el libre flujo y desarrollo de la razón y de la moral. Una vez alcanzado dicho punto el Estado, tal como lo conocemos, se volvería en principio superfluo ${ }^{85}$. En efecto, tanto el desacuerdo político como la toma de decisiones perderían su razón de ser bajo dichas condiciones ideales. Agentes igualmente racionales y morales no tendrían por qué estar en desacuerdo sobre cuestiones políticas, ni, por supuesto, tendrían que preocuparse en cómo resolverlo. De hecho, tanto el imperialismo cuanto el terrorismo serían imposibles por definición. Sin embargo, si por alguna extraña razón el desacuerdo reapareciera luego de que se instituyera este mejor régimen, o qué decir si reaparecieran el imperialismo y/o el terrorismo, la única explicación posible sería que la irracionalidad y la inmoralidad de los agentes son más resistentes de lo que se creía, y la reacción de nuestro Estado ideal sería la típicamente moral de tratar la inmoralidad con el castigo, o la de poner en contexto mediante una explicación la conducta en cuestión rastreándola hasta las nuevas instituciones, las cuales serían en el fondo las responsables de los actos criminales. En el medio habría solamente contradicción o sadismo. En otras palabras, las alternativas seguirían siendo las mismas que hoy en día.

En última instancia, toda acción justificadamente condenable y/o punible se debe a una decisión por parte de quien realizó dicha acción. En el caso del terrorismo, y tal como sostiene Walzer, «todo nuevo actor, terrorista o contraterrorista, pretende estar reaccionando contra alguien más, ubicándose en un círculo y simplemente haciendo circular el mal [just passing the evil along]. Pero este círculo es ideológico en carácter; de hecho, todo actor es un agente moral y toma una decisión independiente» ${ }^{86}$.

La conclusión parece ser entonces que Kant en el fondo tenía razón. En última instancia, toda acción moral, y especialmente en el caso de actos claramente inmorales como los terroristas, es inexplicable, al menos desde el punto de vista del razonamiento jurídico:

${ }^{85} \mathrm{Cfr}$. Carl Schmitt, Der Leviathan in der Staats/ehre des Thomas Hobbes. Sinn und Fehlschlag eines politischen Symbols, ed. Günther Maschke, Stuttgart, Klett-Cotta, 1982, p. 55.

${ }^{86}$ Michael Walzer, p. 60. 
«Cualquier transgresión de la ley puede explicarse del siguiente modo y no puede explicarse de ningún otro: que la transgresión surge de una máxima del delincuente (la máxima de darse a sí mismo tal crimen como regla); porque si la deriváramos de un impulso sensible, no la habría cometido como un ser libre y no podríamos imputársela; pero es completamente imposible explicar cómo el sujeto puede adoptar una máxima semejante contra la clara prohibición de la razón legisladora, porque sólo los acontecimientos que se producen siguiendo el mecanismo de la naturaleza son explicables» ${ }^{87}$.

Esta incompatibilidad entre la explicación en sentido estricto y la condena moral muestra un punto clave acerca de la libertad radical humana. Los seres humanos son responsables por las decisiones que toman pero en última instancia no pueden explicar (en el sentido estricto de la expresión) por qué toman sus decisiones morales, se trate de ser funcionarios del Departamento de Estado, cometer actos terroristas, genocidios, o lo que fuera. No solamente son inescrutables, sino que deben serlo, ya que eso es precisamente lo que significa ser una persona libre y responsable ${ }^{88}$. El caso de la violencia política no es una excepción.

\section{Registro bibliográfico}

ROSLER, ANDRÉS

«La violencia política entre el delito político y el terrorismo», en: ESTUDIOS SOCIALES, revista universitaria semestral, año XXV, no 48, Santa Fe, Argentina, Universidad Nacional del Litoral, primer semestre de 2015, pp. 105-133.
Recibido: 05 / 02 / 2014

Aprobado: 20 / 03 / 2015

87 Immanuel Kant, Metafísica de las costumbres, op. cit., p. 153.

88 Ver: Richard Bernstein, Radical Evil: a Philosophical Investigation, Oxford, Polity, 2002, pp. 44 y $98-99$. 
